\title{
Monitoring of Growth and Production Characteristics of Red Yeasts Cultivated on Hydrothermally Pretreated Lignocellulosic Pine Material
}

\author{
A. Haronikova, ${ }^{a}$ G. Liden, ${ }^{b}$ and I. Marova ${ }^{a},{ }^{, *}$ \\ ${ }^{a}$ Materials Research Centre, Faculty of Chemistry, \\ Brno University of Technology, Purkyňova 464/118, \\ 61200 Brno, Czech Republic \\ bDepartment of Chemical Engineering, Lund University, \\ P.O. Box 124, SE-221 00 Lund, Sweden
}

doi: 10.15255/CABEQ.2015.2313

Original scientific paper Received: October 12, 2015

Accepted: November 29, 2017

\begin{abstract}
The aim of this work was to compare the production of carotenes and ergosterol by red yeasts grown on pine lignocellulose substrates. The yeast strains Rhodotorula aurantiaca and Sporobolomyces shibatanus were grown on the liquid fraction of steam pretreated pine $\left(210{ }^{\circ} \mathrm{C}\right.$, catalyst $\left.\mathrm{SO}_{2}\right)$. Biomass production on a pine hydrolysate was lower than on glucose. The highest content of carotenoids and ergosterol in the cells of $R$. aurantiaca grown on pine hydrolysate was about $1.7 \mathrm{mg} \mathrm{g}^{-1}$ and $0.8 \mathrm{mg} \mathrm{g}^{-1}$ (dwt), respectively, and in S. shibatanus about $0.9 \mathrm{mg} \mathrm{g}^{-1}$ and $0.1 \mathrm{mg} \mathrm{g}^{-1}$, respectively.

Hemicellulose hydrolysates may contain many compounds that have inhibitory effects on microorganisms. In this work, the influences of some inhibitors were assessed by cultivating yeasts on media with a representative addition of the selected compounds. From these tests, furfural appears to be the most critical inhibitor, whereas acetic acid and 5-hydroxymethyl furfural (HMF) do not affect the growth so much.
\end{abstract}

Key words:

lignocellulose, steam pretreatment, red yeasts, carotenoids, ergosterol

\section{Introduction}

Carotenoids, such as unsaturated isoprene derivates, are the most distributed class of pigments in nature with orange, yellow or red colour. These pigments have a wide range of industrial applications. They provide attractive colour and antioxidant activity in food products, and some pigments act as vitamin A precursors in food and animal feed. Possible tumour inhibiting activity has been reported ${ }^{1}$, and also enhancement of the immune response leading to protection against infections ${ }^{2}$. Lycopene, a carotenoid pigment, could be useful in prevention of heart diseases and several types of cancers ${ }^{3}$. $\beta$-carotene has specific functions, such as photoprotection by light absorbing capacity, and acts as a precursor of vitamin A and specific hormones. It therefore reduces cell damage ${ }^{4}$.

Carotenoids are produced by filamentous fungi and yeasts like Blakeslea trispora, Phaffia sp., Rhodotorula sp., and by some species of bacteria and algae, such as Dunaliella sp., and Flavobacterium sp. ${ }^{5-8}$ Commercial interests are primarily directed towards the fungus Blakeslea sp. and yeasts

\footnotetext{
${ }^{*}$ Corresponding author: Marova Ivana, Prof.; E-mail address: marova@fch.vutbr.cz; Phone: +420 541149419
}

Phaffia sp. and Rhodotorula sp. ${ }^{5}$ The microbial production of carotenoids is of interest mainly because of economic advantages of using low-cost natural substrates as sources of carbohydrates, compared with the direct extraction from vegetables or production by chemical synthesis ${ }^{8,9}$. Red yeasts are able to utilize a number of carbon sources, such as glucose, xylose, glycerol, and others ${ }^{9-10,13-14}$.

To reduce the cost of biotechnological processes, the influence of process conditions have been studied, including effects of physical and nutritional factors, such as minerals, vitamins, aeration, $\mathrm{pH}$, temperature, lighting or stress factors. Stress brings biochemical responses involving an increase in the activity of enzymes, which can result in increased production of carotenoids ${ }^{10}$. A number of studies have investigated carotenoids production by use of cheap industrial by-products as nutrient sources oats, wheat, grape must, hydrolysed mung bean waste flour, peat extract, sugar molasses, cheese whey, lipids and related substances, glycerol or lignocellulosic materials, to obtain the maximum amount of desired product, and moreover it is economical as well as ecological ${ }^{9-14}$. However, to the best of the author's knowledge, lignocellulose hydrolysates from softwood pine have not been reported for cultivation of red yeasts. 
The aim of the present paper was to assess the use of hemicellulose hydrolysates from pine, obtained by steam pretreatment, as an alternative carbon source for production of carotenoids and selected lipid metabolites. Presently, lignocellulosic biomass is of interest for the production of bioethanol, since it allows the use of agricultural and forestry residues, and thereby reduces the net greenhouse gas emissions in comparison to starch-derived (so-called) first generation biofuels ${ }^{15,16}$. However, lignocellulose is a complex mixture of macromolecules, such as cellulose, hemicellulose and lignin, which are not directly fermentable. Therefore, methods to degrade this material are needed to obtain simpler sugars that can be utilized by various microorganisms. In this work, steam pretreatment was used. The basic principle of steam pretreatment is that the feedstock is heated using high-pressure stream to a temperature of typically $180-230{ }^{\circ} \mathrm{C}$ for a short time ${ }^{17,18}$. Primarily, the hemicellulose, but also to some extent, the cellulose is hereby hydrolysed into monosaccharides, which can then be used in the production of biomass and desired metabolites by microorganisms such as yeasts ${ }^{19}$.

During steam pretreatment, many types of compounds are formed in addition to the sugars. These compounds may be potential inhibitors affecting the microorganisms. Examples include aliphatic and uronic acids, and acetic acid - a significant inhibitor, which is formed from acetylated hemicellulose sugars. Also, many aromatic inhibitors, such as ferulic acid or caffeic acid are found as a result of lignin degradation. Other inhibitors are formed by degradation of monosaccharides, for example, furans 2-furaldehyde (furfural) and 5-hydroxymethylfurfural (HMF). These compounds are known to exhibit a strong inhibiting effect on the metabolism of yeast ${ }^{17-19}$.

There are three main mechanisms of inhibition of cellular functions: increased cellular maintenance energy needs, direct inhibition of the metabolic pathways or increase in osmotic stress. The low molecular inhibitors are generally more toxic to microorganisms than high molecular inhibitors with similar chemical functional groups due to higher cell permeability ${ }^{20}$.

In the present investigation, the growth characteristics of two strains of red yeasts - Rhodotorula aurantiaca and Sporobolomyces shibatanus were determined on not only hemicellulose hydrolysates from pine, but also on a synthetic sugar based medium with an addition of some of the known inhibitors, as well as on a purely synthetic medium. Also, the abilities of the yeasts to produce carotenoids in hydrolysate of pine and in the presence of the known inhibitors acetic acid, furfural and HMF were evaluated. It appears that the effect of these inhibitors could explain the results obtained in pine hydrolysates. Accumulation of carotenoid pigments typically occurs during stationary phase. However, the presence of inhibitors from hydrolysate in production medium may very much delay or even prevent the yeast cells from reaching this phase $\mathrm{e}^{21-22}$.

\section{Materials and methods}

\section{Microorganisms and cell cultivation}

The red yeast strains Rhodotorula aurantiaca (RA) and Sporobolomyces shibatanus (SSh) were obtained from the Culture Collection of Yeasts (CCY, Institute of Chemistry, Slovak Academy of Sciences, Bratislava, Slovakia). Yeast strains were stored for further use on malt agar at $4{ }^{\circ} \mathrm{C}$.

Yeasts were cultivated using two-step inoculation as follows ${ }^{22}$ :

Firstly, the yeasts cells were inoculated into 50 $\mathrm{mL}$ of inoculum medium I containing $\left(\mathrm{g} \mathrm{L}^{-1}\right)$ glucose 40, $\left(\mathrm{NH}_{4}\right)_{2} \mathrm{SO}_{2} 5, \mathrm{KH}_{2} \mathrm{PO}_{4} 5, \mathrm{MgSO}_{4} \cdot 7 \mathrm{H}_{2} \mathrm{O}$ 0.696 , yeast extract 7 , and cultivated for $24 \mathrm{~h}$. The inoculum I was then transferred into the second inoculum (Inoculum II; the same composition as Inoculum I) using the volume ratio 1:5 $(10 \mathrm{~mL}+50$ $\mathrm{mL}$ ), and cultivated for $24 \mathrm{~h}$. The fermentation was then started by inoculation of $25 \mathrm{~mL}$ of Inoculum II into a production medium $(125 \mathrm{~mL}$; ratio $1: 5)$ containing $\left(\mathrm{g} \mathrm{L}^{-1}\right)$ : glucose $30,\left(\mathrm{NH}_{4}\right)_{2} \mathrm{SO}_{2} 4, \mathrm{KH}_{2} \mathrm{PO}_{4} 4$, $\mathrm{MgSO}_{4} \cdot 7 \mathrm{H}_{2} \mathrm{O}$ 0.696. The production phase lasted $80 \mathrm{~h}$, and was made aerobically at $25^{\circ} \mathrm{C}$, with permanent lighting and shaking at $90 \mathrm{rpm}$.

\section{Raw material and pretreatment}

Material of Scots pine (Pinus sylvestris) was obtained from the Agricultural University of Sweden (SLU), Umeå. The sapwood fraction of the pine material was used in the work, and this was impregnated in closed plastic bags with $\mathrm{SO}_{2}(2.5 \% \mathrm{w} / \mathrm{W}$ moisture) for $20 \mathrm{~min}$. Subsequently, it was subjected to steam pretreatment at $210{ }^{\circ} \mathrm{C}$ for $5 \mathrm{~min}$ in a pressure reactor system described by Palmqvist et al. ${ }^{23}$ The pretreated material was stored at $4{ }^{\circ} \mathrm{C}$. The slurry was separated by filtration into a solid fraction and a liquid fraction. The composition of the two fractions of pretreated materials, i.e. the washed water insoluble fibre fraction and the liquid fraction are shown in Table 1. Only the liquid fraction, containing mainly sugars derived from the hemicellulose part, was used in the experiments.

\section{Yeast cultivation on pine hydrolysate}

Cultivation experiments on pretreated pine hydrolysate were performed in two series: A and B, which differed in the glucose/hydrolysate ratio. The 
Table 1 -Composition of pretreated pine material

\begin{tabular}{cccc}
\hline $\begin{array}{c}\text { Content in solid fraction } \\
\text { (\% of dry weight) }\end{array}$ & $\begin{array}{c}\text { Content in liquid fraction } \\
\left(\mathrm{g} \mathrm{L}^{-1}\right)\end{array}$ \\
\hline Glucan & 47 & Glucose & 40 \\
Mannan & 2.2 & Mannose & 22 \\
Xylan & 0 & Xylose & 9 \\
Lignin & 53.9 & Furfural & 3.7 \\
& & HMF & 4.2 \\
& & Acetic acid & 3.9 \\
\hline
\end{tabular}

Note: HMF - hydroxymethyl furfural

cultures were firstly grown in inoculation medium with glucose content $40 \mathrm{~g} \mathrm{~L}^{-1}$ (in series A, Inoculum I and II, see above). For better and faster adaptation of yeasts on different carbon sources in production media, in the series B, Inoculum I was of the same composition as in the series A, while Inoculum II contained both pine hydrolysate and glucose as the carbon source at the ratio of $1: 1\left(20 \mathrm{~g} \mathrm{~L}^{-1}\right.$ of glucose $/ 20 \mathrm{~g} \mathrm{~L}^{-1}$ of hydrolysate). The hydrolysate contained glucose, mannose and xylose $\left(40 \mathrm{~g} \mathrm{~L}^{-1}, 20 \mathrm{~g} \mathrm{~L}^{-1}\right.$ and $9 \mathrm{~g} \mathrm{~L}^{-1}$, respectively).

The fermentation was carried out in the production medium containing glucose $\left(30 \mathrm{~g} \mathrm{~L}^{-1}\right)$ as a control medium. In the pine hydrolysate experiments, glucose was fully substituted with pine hydrolysate to give exactly $30 \mathrm{~g} \mathrm{~L}^{-1}$ of total sugars (denoted $100 \%$ hydrolysate). When examining mixed media, the \%-level refers to the relative contribution of sugars. Thus, media with $75 \%$ of hydrolysate contained $22.5 \mathrm{~g} \mathrm{~L}^{-1}$ of total sugars from the hydrolysate fraction, $50 \%$ contained $15 \mathrm{~g} \mathrm{~L}^{-1}$ of sugars from the hydrolysate fraction, and so on. Pure glucose made up the remaining part up to a total sugar concentration of $30 \mathrm{~g} \mathrm{~L}^{-1}$. In total, 5 types of production media for each $\mathrm{A}$ and $\mathrm{B}$ series were used: control (glucose $30 \mathrm{~g} \mathrm{~L}^{-1}$ ); hydrolysate (42 mL containing $30 \mathrm{~g} \mathrm{~L}^{-1}$ of saccharides); $75 \%$ hydrolysate $\left(32 \mathrm{~mL}\right.$ of hydrolysate $+7.5 \mathrm{~g} \mathrm{~L}^{-1}$ of glucose), $50 \%$ hydrolysate $(21 \mathrm{~mL}$ of hydrolysate + $15 \mathrm{~g} \mathrm{~L}^{-1}$ glucose), $25 \%$ hydrolysate $(11 \mathrm{~mL}$ of hydrolysate $+22.5 \mathrm{~g} \mathrm{~L}^{-1}$ of glucose).

Two cultivation experiments, each with two parallel cultivations (four cultivations in total) were performed for all experiments.

\section{Growth characteristics on sugars and effect of inhibitors from hydrolysate on the growth}

Glucose, xylose and mannose are the main sugars in the hemicellulose hydrolysate of pine (i.e. the liquid fraction in Table 1). Carotenogenic yeasts were cultivated on each sugar individually and on a mixture mimicking the sugar composition of the pine hydrolysate in Table 1. Growth characteristics of these yeasts were monitored to determine wheth- er the pathways of utilization of these sugars are different. Further, it was of interest to determine which of the inhibitors present in a liquid fraction are critical components affecting the growth of the red yeasts. Therefore, the selected inhibitors were added to the medium individually at the concentrations as shown in Table 1. Yeast cultivations were performed for $53 \mathrm{~h}$, aerobically at $25{ }^{\circ} \mathrm{C}$, with permanent lighting and shaking at $90 \mathrm{rpm}$. Two parallel cultivations were performed for each condition.

\section{Extraction and analysis of microbial metabolites}

After cultivation, the cells were harvested by centrifugation $(5000 \mathrm{rpm}, 10 \mathrm{~min})$. The cells were disintegrated by mechanical disruption with addition of acetone. After saponification of the extract by $10 \%$ ethanolic $\mathrm{KOH}\left(30 \mathrm{~min}, 90{ }^{\circ} \mathrm{C}\right)$, carotenoids and sterols were extracted three times with diethyl ether. The diethyl ether extracts were collected and evaporated under vacuum to dryness. After evaporation, the residue was dissolved in absolute ethanol and analysed by HPLC. Samples were filtered through PTFE filters and injected onto column C18. Separation was carried out by isocratic elution at $45{ }^{\circ} \mathrm{C}$. The mobile phase used was meth-

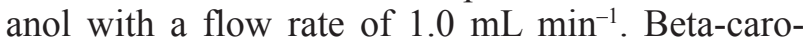
tene, ergosterol, as well as total carotenoids were individually identified and quantified by RP-HPLC/ PDA (Thermo Scientific, Waltham, Massachusetts, USA). Individual carotenoids were quantified at $450 \mathrm{~nm}$ using external standard of beta-carotene. Ergosterol was analysed in the same filtered extract as pigments. Separation was carried out in the same column as carotenoids using UV detection at 285 $\mathrm{nm}$ for identification. Ergosterol was quantified using external standard of ergosterol ${ }^{22}$. Descriptive statistical analysis of selected metabolic parameters was performed by evaluation of standard deviation (Statistica v.12, StatSoft CZ).

\section{Results and discussion}

\section{The cultivation on pretreated hydrolysate of pine}

The aim of this work was to assess possibilities of utilization of pretreated pine substrate as a carbon source for production of carotene-enriched biomass by two strains of red yeasts; Rhodotorula aurantiaca and Sporobolomyces shibatanus. Media with different ratios of hydrolysate and glucose were used for cultivation of these yeasts. Furthermore, the effect of adaptation of the yeast to the medium containing pine hydrolysate was investigated by comparing cultivations with yeasts pregrown on synthetic medium (series A) and with yeasts pregrown on a medium containing hydrolysate (series 
B, Inoculum II). Morphological changes are visible indicators of microbial adaptation to environmental variations. After $80 \mathrm{~h}$ of cultivation, the yeasts were observed under microscope to see morphological changes (not shown). Cells in media with addition of pine hydrolysate were wrinkled and of uneven shape, which indicates stress effects.

A first estimate of production of carotenoids was also made visually from the colour of the medium. The cultivation with addition of different portions of hydrolysate resulted in various colouring of media. The media with $100 \%$ hydrolysate had a paler colour. This was seen mainly in the series B, where the low final biomass concentration was the main factor.

The final biomass concentration decreased for both yeast strains with increasing fraction of hydrolysate in the medium in comparison to the reference medium (Table 2). This was to be expected, as the hydrolysate most probably contained some components that have a negative impact on cell growth. In media where the carbon source was fully substituted by hydrolysate, the production of biomass was about $50 \%$ lower than in control media. The final biomass concentrations were somewhat higher for $R$. aurantiaca than for $S$. shibatanus.

The adaptation tested (series B) in general resulted in even lower production of biomass than in the series A. The only exception was for growth on control media, where addition of hydrolysate into the inoculation medium actually gave an increased final biomass concentration (Table 2). The cells of $R$. aurantiaca with $25 \%$ content of hydrolysate sugars in the production media reached similar biomass concentrations as those of the control medium.

The addition of hydrolysate of pine was found not to only have negative effect on production of biomass, but interestingly, certain concentrations could have had a positive influence on carotenogenesis in the yeast cells. In the medium in which $75 \%$ of sugars was supplied by the pine hydrolysate, the cellular content of pigments was 2.5 times higher than in control medium for $R$. aurantiaca cells (series A), and the specific beta-carotene level was higher. However, this was not the case where the carbon source was entirely provided by the hydrolysate (Fig. 1).

The results with $S$. shibatanus were somewhat different. At high concentration of pine hydrolysate, the cellular content of both $\beta$-carotene and total carotenoids was low. However, for the medium with $25 \%$ of hydrolysate, the cellular content of total pigments had increased 2.4 times compared to the control (Fig. 2).

Increased $\beta$-carotene production has previously been reported for growth on different industrial
Table 2 -Production of biomass and $\beta$-carotene using pretreated hydrolysate of pine by carotenogenic yeasts

\begin{tabular}{|c|c|c|}
\hline & Biomass $\left(\mathrm{g} \mathrm{L}^{-1}\right)$ & $\begin{array}{l}\text { Beta-carotene } \\
\left(\mathrm{mg} \mathrm{g}^{-1} \mathrm{dwt}\right)\end{array}$ \\
\hline RA control A & $7.7 \pm 0.11$ & $248 \pm 16.5$ \\
\hline RA control B & $7.9 \pm 0.10$ & $228 \pm 11.1$ \\
\hline RA $100 \% \mathrm{H} \mathrm{A}$ & $3.6 \pm 0.05$ & $201 \pm 13.1$ \\
\hline RA $100 \%$ H B & $3.0 \pm 0.04$ & $100 \pm 7.9$ \\
\hline RA $75 \%$ H A & $5.5 \pm 0.06$ & $326 \pm 21.6$ \\
\hline RA $75 \%$ H B & $4.6 \pm 0.04$ & $181 \pm 15.4$ \\
\hline RA $50 \% \mathrm{H} \mathrm{A}$ & $6.2 \pm 0.08$ & $241 \pm 18.6$ \\
\hline RA $50 \% \mathrm{H} \mathrm{B}$ & $5.9 \pm 0.07$ & $141 \pm 12.1$ \\
\hline RA $25 \% \mathrm{H} \mathrm{A}$ & $7.9 \pm 0.09$ & $204 \pm 15.5$ \\
\hline RA $25 \%$ H B & $6.9 \pm 0.10$ & $144 \pm 12.8$ \\
\hline SSh control A & $6.2 \pm 0.13$ & $94 \pm 5.4$ \\
\hline SSh control B & $6.6 \pm 0.15$ & $128 \pm 12.2$ \\
\hline SSh $100 \% \mathrm{H} \mathrm{A}$ & $2.9 \pm 0.05$ & $51 \pm 3.8$ \\
\hline SSh $100 \%$ H B & $2.9 \pm 0.05$ & $41 \pm 4.6$ \\
\hline SSh $75 \%$ H A & $3.6 \pm 0.06$ & $28 \pm 3.1$ \\
\hline SSh $75 \%$ H B & $3.6 \pm 0.07$ & $51 \pm 6.53$ \\
\hline $\mathrm{SSh} 50 \% \mathrm{H} \mathrm{A}$ & $3.9 \pm 0.06$ & $68 \pm 5.8$ \\
\hline SSh $50 \% \mathrm{H} \mathrm{B}$ & $4.2 \pm 0.05$ & $59 \pm 6.9$ \\
\hline SSh $25 \%$ H A & $5.8 \pm 0.04$ & $129 \pm 14.1$ \\
\hline $\mathrm{SSh} 25 \% \mathrm{H} \mathrm{B}$ & $4.9 \pm 0.08$ & $156 \pm 17.1$ \\
\hline
\end{tabular}

(Rhodotorula aurantiaca - RA, Sporobolomyces shibatanus $\mathrm{SSh}$, Hydrolysate - H, Glucose - control, series A - A, series $B-\mathrm{B})$

Realization of experiments is described in section Materials and methods (Yeast cultivation on pine hydrolysate).

Results of biomass and metabolites yield were expressed as average values of four ( $2 x$ two) parallel cultivations. Results of beta-carotene were quantified using area under chromatogram $(450 \mathrm{~nm})$ and calibration curve for beta-carotene ${ }^{19}$.

by-product materials, such as sugarcane molasses or grape must, with reported cellular contents in Rhodotorula spp. of about $2.36 \mathrm{mg}$ of total carotenoids $\mathrm{g}^{-1} \mathrm{dwt}^{13,14}$, whey, potato extract and cereal wastes (about $1.4-1.6 \mathrm{mg} \mathrm{g}^{-1} \mathrm{dwt}$ for Rhodotorula spp. and Sporobolomyces spp. about $2.94-4.54 \mathrm{mg}$ of total carotenoids $\left.\mathrm{g}^{-1} \mathrm{dwt}\right)^{10}$.

The production of ergosterol was very similar to the production of $\beta$-carotene, even if these metabolites were formed in competitive branches of the isoprenoid metabolic pathway.

With respect to the production of ergosterol, the highest content was found for both $R$. aurantia$c a$ and $S$. shibatanus growing in the media with 100 $\%$ pine hydrolysate as a carbon source (Figs. 3, 4). This may be attributed to changes in metabolism of 


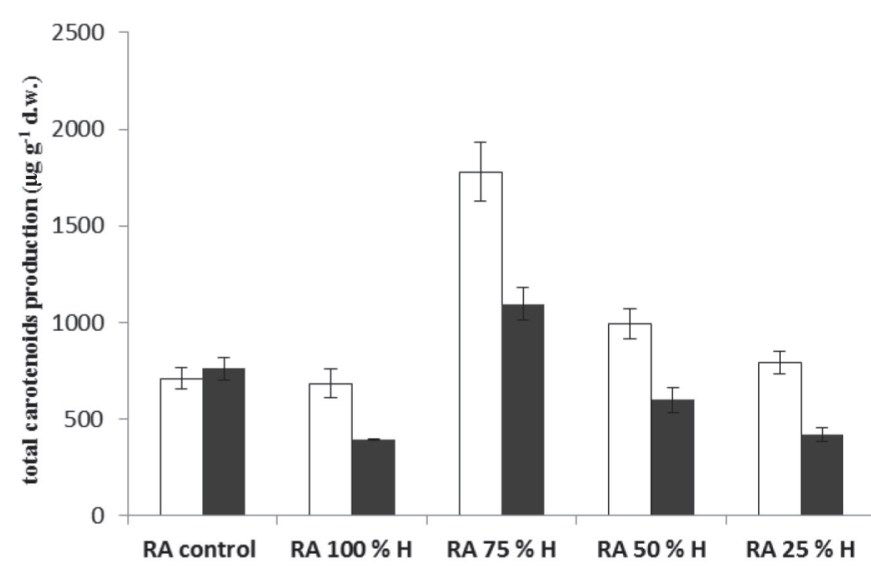

Fig. 1 - Production of total carotenoids by Rhodotorula aurantiaca

Cultivation with addition of different number of hydrolysate: series $A \ldots(\square)$, series $B \ldots(\square)$

Description: RA - Rhodotorula aurantiaca, control - glucose medium, $100 \% \mathrm{H}-100 \%$ saccharides from liquid hydrolysate, $75 \% \mathrm{H}-75 \%$ saccharides from liquid hydrolysate and $25 \%$ of glucose, $50 \% \mathrm{H}-50 \%$ saccharides from liquid hy drolysate and $50 \%$ of glucose, $25 \% \mathrm{H}-25 \%$ saccharides from liquid hydrolysate and $75 \%$ of glucose.

Results of metabolites yield were expressed as average values of four (2x two) parallel cultivations.

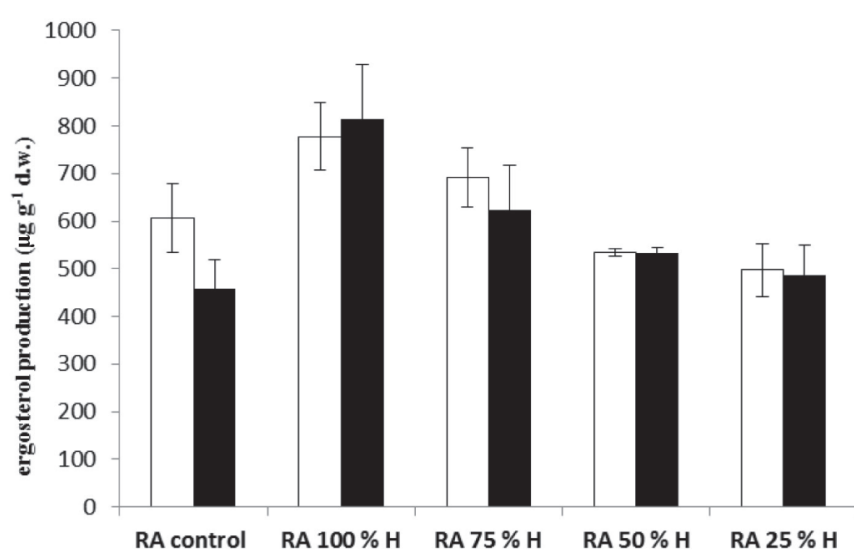

Fig. 3 - Production of ergosterol by Rhodotorula aurantiaca Cultivation with addition of different number of hydrolysate: series $A \ldots(\square)$, series $B \ldots(\square)$

Description: RA - Rhodotorula aurantiaca, medium description - see Fig. 1.

Results of metabolites yield were expressed as average values of four ( $2 x$ two) parallel cultivations.

synthesis of sterols in biomembranes as protection against inhibitors. Ergosterol is an integral component of yeast cell membranes, which are very sensitive to external stress ${ }^{22,24}$.

The results suggest that the studied red yeasts are able to utilize pine hydrolysates as a substrate and produce carotenes and sterols. The use of hydrolysates led to a decrease in the biomass production, but the specific production of $\beta$-carotene and

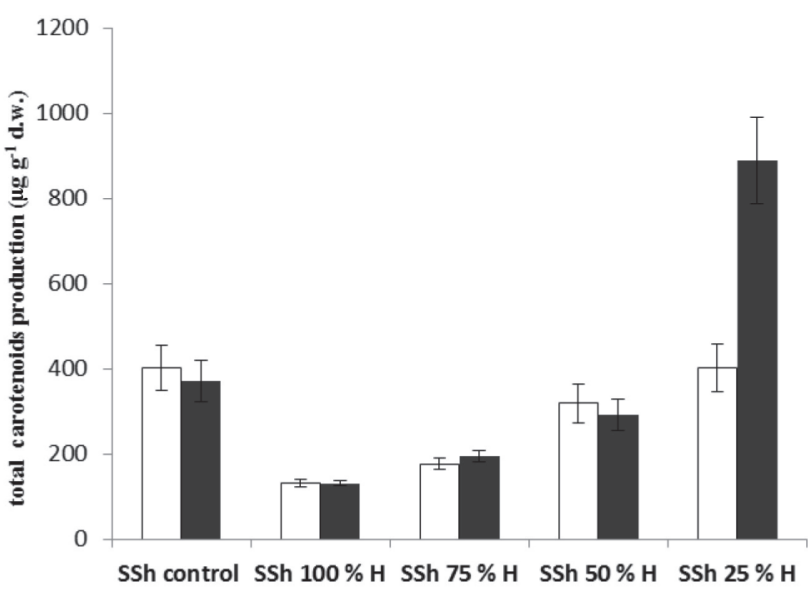

Fig. 2 - Production of total carotenoids by Sporobolomyces shibatanus

Cultivation with addition of different number of hydrolysate: series A...( $\square)$, series $B \ldots(\square)$

Description: SSh - Sporobolomyces shibatanus, medium description - see Fig. 1.

Results of metabolites yield were expressed as average values of four (2x two) parallel cultivations.

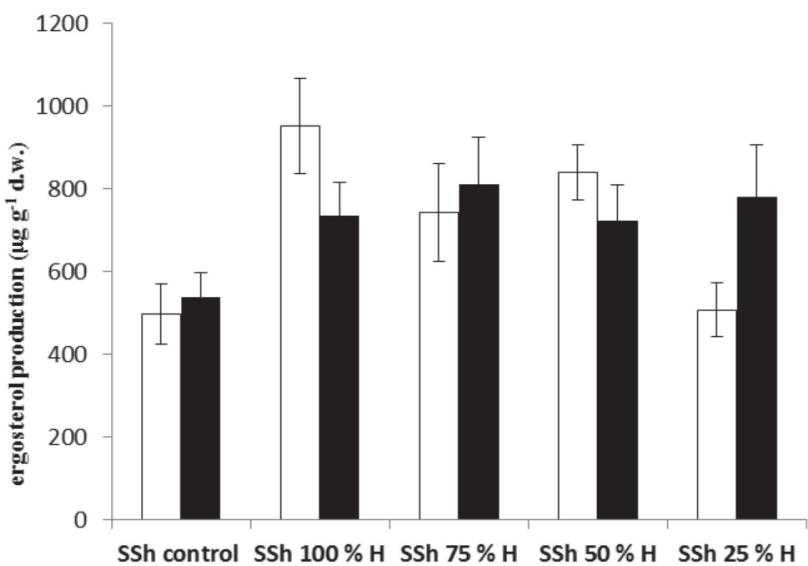

Fig. 4-Production of ergosterol by Sporobolomyces shibatanus

Cultivation with addition of different number of hydrolysate: series $A \ldots(\square)$, series $B \ldots$...(ם)

Description: SSh - Sporobolomyces shibatanus, medium description - see Fig. 1.

Results of metabolites yield were expressed as average values of four (2x two) parallel cultivations.

total carotenoids increased several times on $75 \%$ hydrolysates for $R$. aurantiaca (Fig. 1), RA/A 75 HYDR - $1.7 \mathrm{mg} \mathrm{g}^{-1}$ ) and on $25 \%$ hydrolysates for S. shibatanus (Fig. 2). Also, the production of ergosterol was substantially higher in media with a higher portion of hydrolysates $(100 \%, 75 \%)$ than in control medium, mainly for strains adapted to hydrolysate medium in B series (Fig. 3) RA/B 100 HYDR (6x increase). 
Sporobolomyces shibatanus

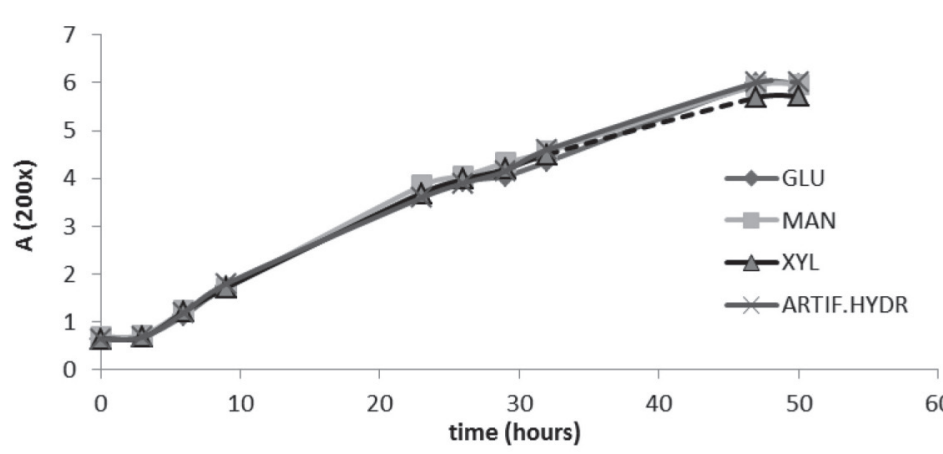

Rhodotorula aurantiaca

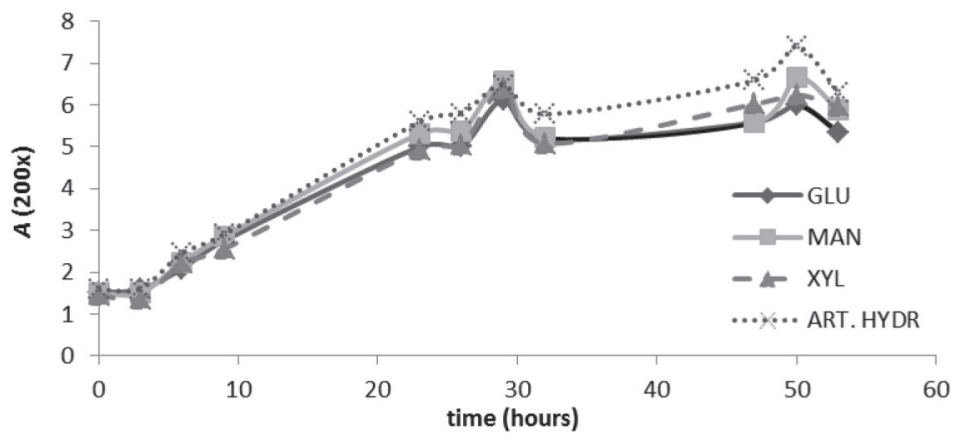

Fig. 5 - Growth curve of Sporobolomyces shibatanus and Rhodotorula aurantiaca on sugars and artificial hydrolysate

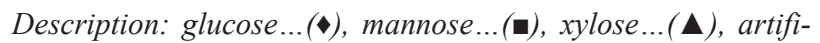
cial hydrolysate...( $\times)$;

Note: In these screening experiments, biomass was analysed turbidimetrically and cell growth expressed as absorbance of the cell culture at $630 \mathrm{~nm}$. Parameter A (200x) means that cell suspension was diluted $20 x$ and values of absorbance 10x lower.

In general, decreased biomass of red yeasts as well as production of metabolites could be partially explained by the effect of inhibitors present in the hydrothermally pretreated pine material, as mentioned previously. Studies by Marova et al. ${ }^{10,22}$ and Aksu and Eren ${ }^{25}$ have shown that, under stress conditions, red yeasts accumulate higher amounts of stress metabolites - carotenoids and ergosterol. Exposition of red yeast cells to stress factors in these previous studies resulted in higher production of carotenoids as well as ergosterol. The production of biomass had changed only slightly. Under high stress (addition of salt or peroxide concentration), a 2-3 times increase in $\beta$-carotene and ergosterol against the control media was observed. The possibility to use these inhibitors as exogenous stress to improve production should be further studied. Different carbon sources, nitrogen sources and other nutrient materials were previously shown to have different influence on cell growth and accumulation of ergosterol in yeast biomass. The ergosterol content increased when the specific growth rate decreased. Food industrial waste materials, such as whey, potato extract, and wheat bran led to increased production of ergosterol by carotenogenic yeast strains Rhodotorula sp. $\left(0.2-0.8 \mathrm{mg} \mathrm{g}^{-1} \mathrm{dwt}\right)$ and Sporobolomyces sp. $\left(0.6-2.35 \mathrm{mg} \mathrm{g}^{-1} \mathrm{dwt}\right.$, in liquid whey substrate, specifically by Sporobolomyces roseus $3.13 \mathrm{mg}$ of ergosterol $\mathrm{g}^{-1} \mathrm{dwt}$ ).

\section{Effect of inhibitory factors from liquid fraction of pretreated pine material}

While growth and production properties of studied yeast strains on pine hydrolysate were substantially lower than on glucose (see Table 2), further experiments were focused on testing the factors causing such inhibitory effects. Hydrothermal pretreatment of lignocellulosic materials leads to formation of a wide spectrum of compounds having inhibitory effects on yeast ${ }^{26}$. Firstly, utilization on individual sugars present in hydrolysate and artificial hydrolysate was tested. In the next experiments, the effect of some of the main inhibitors formed during acid hydrolysis of pine material - acetic acid, furfural and HMF - on the growth of $R$. aurantiaca and $S$. shibatanus was studied.

The yeast strains were cultivated on each sugar individually, on the artificial hydrolysate and on the sugars with addition of inhibitor. The obtained biomass concentration on each sugar individually and artificial hydrolysate was very similar for both $S$. shibatanus and $R$. aurantiaca. No significant differences in cell concentration were found (Fig. 5).

Substantial differences were seen when testing individual inhibitors (Fig. 6). Apparently, both $R$. aurantiaca, and $S$. shibatanus grew well on glucose in the presence of HMF and acetic acid at the concentrations tested. However, furfural appeared to be most critical of the compounds tested, and had a strong inhibitory effect on cell growth (Fig. 6).

Production of biomass and carotenoids on media containing furfural decreased about 30 -fold in comparison to pure glucose medium. The growth kinetics of the yeasts on different sugars as well as combination of sugars and inhibitors was studied as well. A simple model of exponential growth (with a lag phase) was used ${ }^{21}$, i.e.

$$
\frac{\mathrm{d} X}{\mathrm{~d} t}=\mu_{n e t} X
$$

where $X$ is dry weight of biomass $\left(\mathrm{g} \mathrm{L}^{-1}\right), \mu_{\text {net }}$ is net specific growth rate $\left(\mathrm{h}^{-1}\right)$.

Assuming that at $t=t_{0}, X=X_{0}$, equation (1) can be integrated as (2):

$$
\ln \frac{X}{X_{0}}=\mu_{\text {net }}\left(t-t_{0}\right)
$$

Measured biomass concentrations, from the exponential growth phase, were used to determine the specific growth rates in the cultivations (Table 3 ). 
Sporobolomyces shibatanus

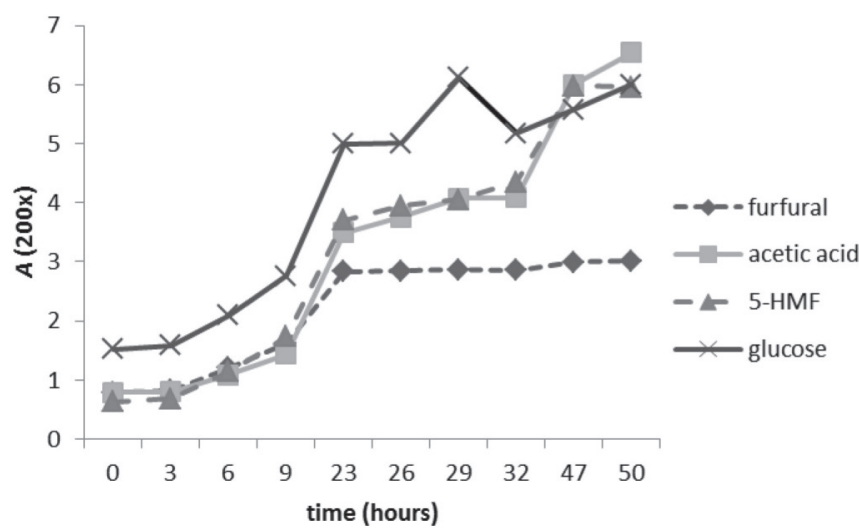

Rhodotorula aurantiaca

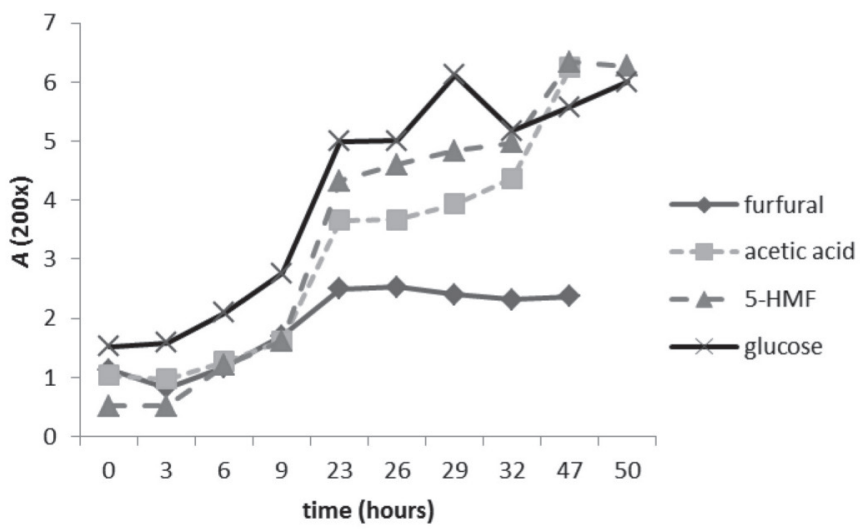

Fig. 6 - Effect of acetic acid, furfural and 5-HMF on growth of Sporobolomyces shibatanus and Rhodotorula aurantiaca grown on glucose medium

Description: glucose + furfural...(»), glucose + acetic acid... (๘), glucose $+5-H M F \ldots(\mathbf{\Delta})$, pure glucose ...( $\times)$.

Note: Biomass was analysed turbidimetrically and cell growth expressed as absorbance of the 20x diluted cell culture at 630 nm (parameter A (200x), see Fig. 5).

The net specific growth rate of $R$. aurantiaca growing on medium with pure glucose decreased from $0.106 \mathrm{~h}^{-1}$ to $0.074 \mathrm{~h}^{-1}$ in the presence 5 -HMF, and decreased to as low as $0.012 \mathrm{~h}^{-1}$ in $100 \%$ hydrolysate as the carbon source.

When comparing the specific growth rates on the individual sugars tested, it was found that the highest specific growth rate for $R$. aurantiaca was for growth on mannose. This is interesting, given the composition of the pine hemicellulose hydrolysate used. In contrast, for $S$. shibatanus, the highest specific growth rate was for growth on glucose. As Table 3 indicates, $R$. aurantiaca cells growth in the medium with mannose and in the presence of inhibitors is less influenced among the media tested. That implies that the high conversion rate of mannose may increase resistance against inhibitory factors in $R$. aurantiaca cells.

The opposite effect was observed in yeast strain $S$. shibatanus. In the medium with mannose and in
Table 3 -Influence of main inhibitors from liquid hydrolysate on the specific growth rates of Rhodotorula aurantiaca and Sporobolomyces shibatanus growing on pure saccharides and artificial hydrolysate

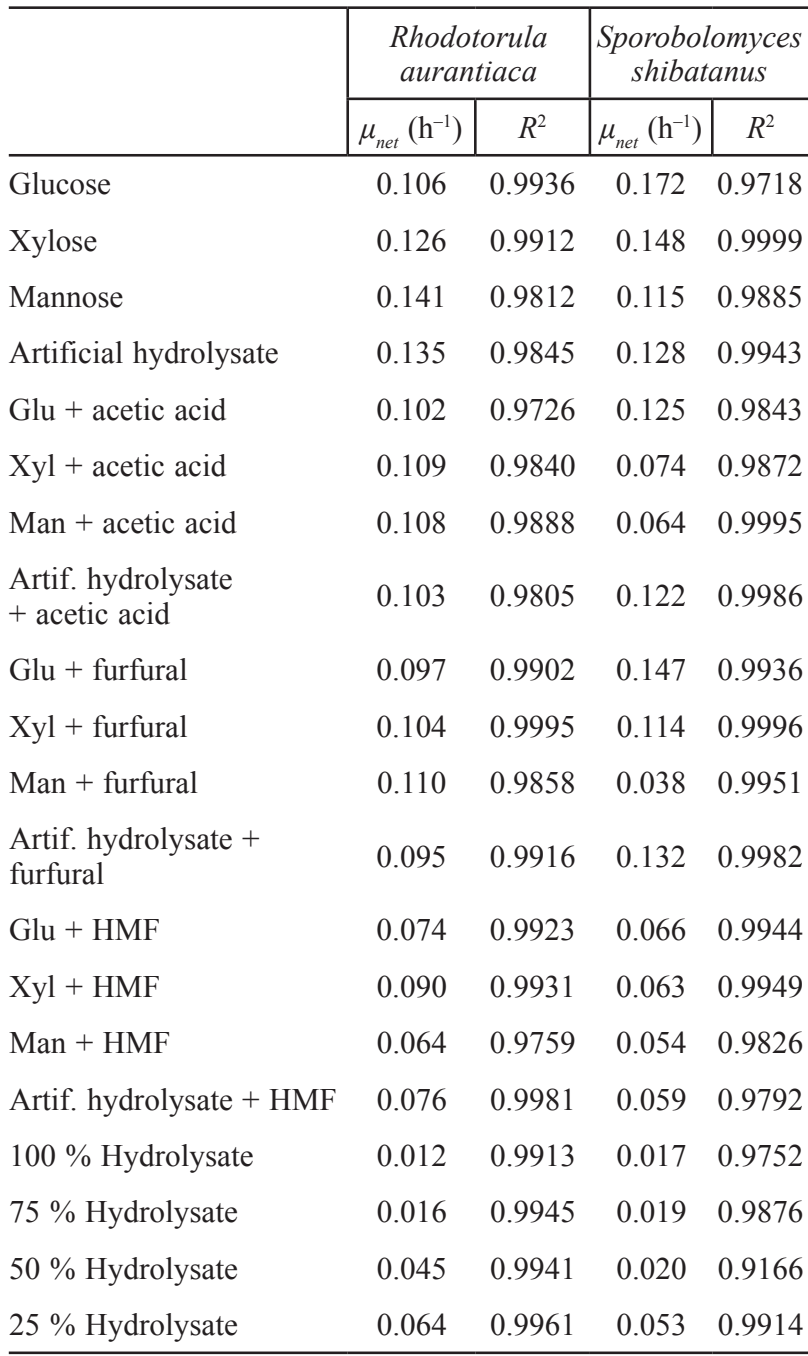

Description: $\mu_{\text {net }}\left(\mathrm{h}^{-1}\right)$ - specific growth rates

The data points within the exponential growth phase were collected for the calculation for each experiment. The plot of relative logarithmic biomass concentration vs time is presented in Fig. 5. These points were determined by polynomial method with Microsoft Excel. The slope of the linear curve is $\mu_{n e t}$.

Results were expressed as average values of two parallel cultivations.

the presence of inhibitors, the lowest specific growth rate was measured and the cells were most strongly influenced. The specific growth rate on mannose was however also the lowest for $S$. shibatanus. For the artifical hydrolysate and in glucose medium with acetic acid, furfural or HMF, $S$. shibatanus was less impacted than with mannose as the only carbon source.

Detoxification of the hydrolysate was not investigated here, but there are several methods of detoxifying hydrolysate ${ }^{20,26}$. Thus, there are options allowing potentially increased carotenoid production from the pine hydrolysate tested here. 

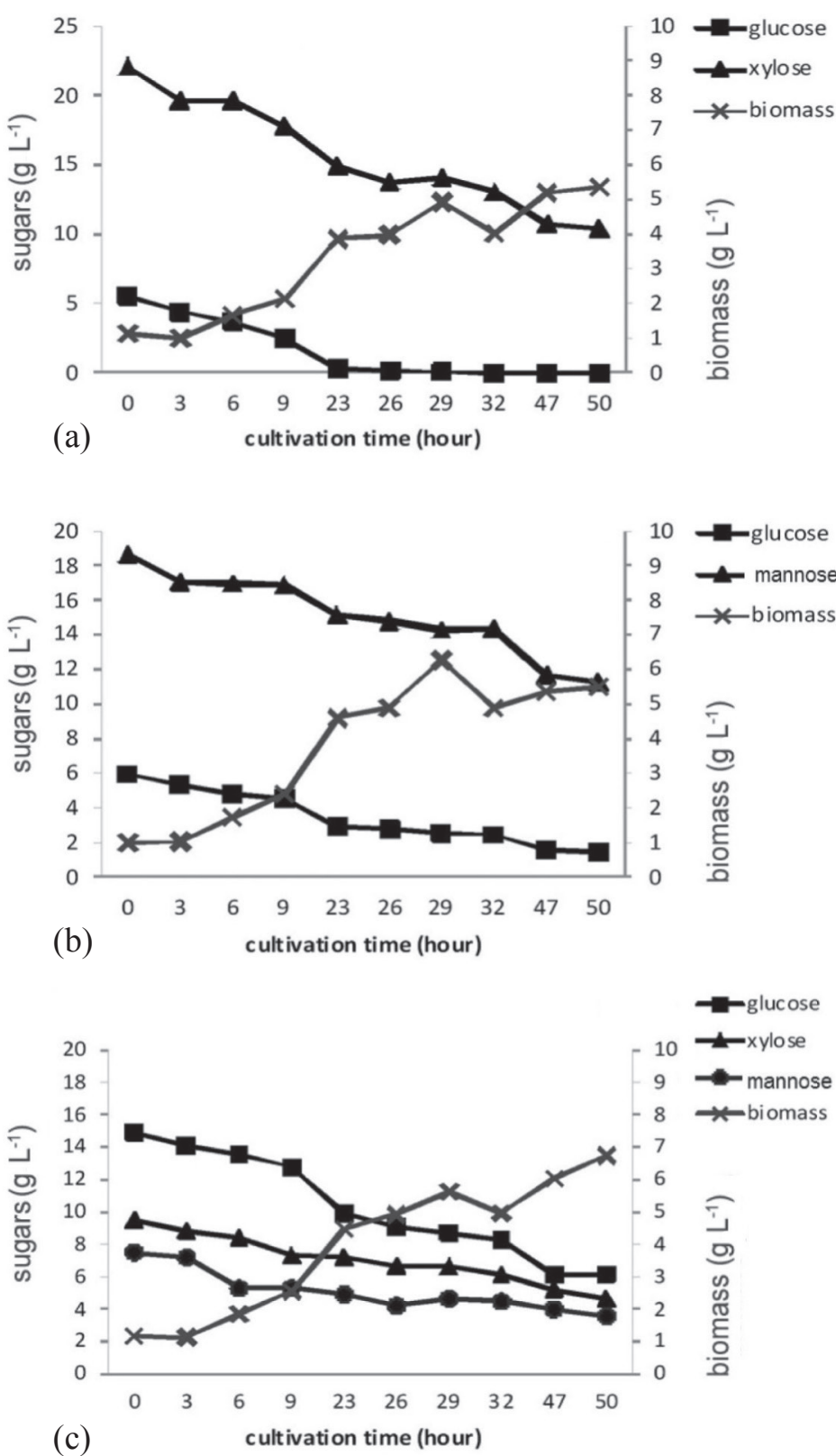

Fig. 7 - Growth of Rhodotorula aurantiaca on medium with xylose (a), mannose (b) and artificial hydrolysate (c), consumption of individual sugars and increase in biomass at the time of $50 \mathrm{~h}$

Description: individual sugars and biomass are expressed as concentration $\mathrm{g} \mathrm{L}^{-1}$

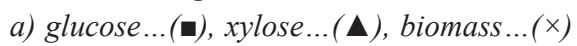

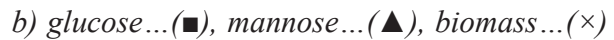

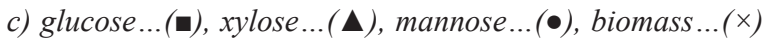

\section{Conclusions}

In this work, it was established that two strains of red yeast, $R$. aurantiaca and $S$. shibatanus, are able to utilize pretreated pine hydrolysate as a substrate. In tested strains, the carotenoid biosynthesis was increased at certain ranges of hydrolysates, giving a higher cell content of the compounds. Thus, the red yeasts may be promising microogranisms for the commercial production of lipid-soluble pigments, sterols and carotene-enriched biomass by using lignocellulosic pine waste as a cheap carbon source. Furfural seems to be the most critical inhibitor component for these strains.

\section{ACKNOWLEDGEMENTS}

This work was financially supported by the project "Centre for Materials Research at FCH BUT - Sustainability and Development" No. LO1211 of the Ministry Education of the Czech Republic and by Regional Strategy Brno. G. Liden also wishes to acknowledge the support of the Bo Rydin foundation to the project TALLRAFF and to $S L U$, Umea for providing the pine material. The authors are grateful to Henrik Almqvist and Sara Johansson, Department of Chemical Engineering, Lund University, for help with some of the analyses.

\section{References}

1. Ben-Dor, A., Nahum, A., Danilenko, M., Giat, Y., Stahl, W., Martin, H. D., Emmerich, T. Noy, N., Levy, J., Sharoni, Y., Effects of acyclo-retinoic acid and lycopene on activation of the retinoic acid receptor and proliferation of mammary cancer cells, Arch. Biochem. Biophys. 391 (2001) 295. doi: https://doi.org/10.1006/abbi.2001.2412

2. Mayne, S. T., Beta-carotene, carotenoids, and disease prevention in humans, The FASEB J. 10 (1996) 690.

3. Nishino, H., Tokuda, H., Satomi, Y., Masuda, M., Bu, P., Onozuka, M., Yamaguchi, S., Okuda, Y., Takayasu, J., Tsuruta, J., Okuda, M., Ichiishi, E., Murakoshi, M., Kato, T., Misawa, N., Narisawa, T., Takasuka, N., Yano, M., Cancer prevention by carotenoids, Pure Appl. Chem. 71 (1999) 2273. doi: https://doi.org/10.1351/pac199971122273

4. Bauernfeind, J. C., Carotenoids as colorants and vitamin A precursors. In: Stewart, G., Schweigert, B., and Hawthorn, J. (Eds.). Technological and Nutritional Applications. New York, Academic Press, NY, USA (1981) 47.

5. Mantzouridou, F., Roukas, T., Kotzekidou, P., Effect of the aeration rate and agitation speed on $\beta$-carotene production and morphology of Blakeslea trispora in a stirred tank reactor: mathematical modelling, Biochem. Eng J. 10 (2002) 123.

doi: https://doi.org/10.1016/S1369-703X(01)00166-8

6. Aksu, Z., Eren A. T., Production of carotenoids by the isolated yeast of Rhodotorula glutinis, Biochem. Eng. J. 35 (2007) 107. doi: https://doi.org/10.1016/j.bej.2007.01.004

7. Yurkov, A. M., Vustin, M. M., Tyaglov, B. V., Maksimova, I. A., Sineokiy, S. P., Pigmented basidiomycetous yeasts area promising source of carotenoids and ubiquinone Q10, Microbiology 77 (2008) 1. doi: https://doi.org/10.1134/S0026261708010013

8. Frengova, G. I., Beshkova, D. M., Carotenoids from Rhodotorula and Phaffia: Yeasts of biotechnological importance, J. Ind. Microbiol. Biotechnol. 36 (2009) 163. doi: https://doi.org/10.1007/s10295-008-0492-9 
9. Frengova, G. I., Simova, E. D., Pavlova, K. G., Beshkova D. M., Grigorova, D. A., Formation of carotenoids by Rhodotorula glutinis in whey ultrafiltrate, Biotechnol. Bioeng. 44 (1994) 888

doi: https://doi.org/10.1002/bit.260440804

10. Marova, I., Carnecka, M., Halienova, A., Certik, M., Dvorakova, T., Haronikova, A., Use of several waste substrates for carotenoid-rich yeast biomass production, J. Environ. Manag. 95 (2012) S338.

doi: https://doi.org/10.1016/j.jenvman.2011.06.018

11. Simova, E. D., Frengova, G. I., Beshkova D. M., Synthesis of carotenoids by Rhodotorula rubra GED8 co-cultured with yogurt starter cultures in whey ultrafiltrate, J. Ind. Microbiol. Biotechnol. 31 (2004) 115. doi: https://doi.org/10.1007/s10295-004-0122-0

12. Frengova, G. I., Simova, E. D., Beshkova, D. M., Caroteno-protein and exopolysaccharide production by co-cultures of Rhodotorula glutinis and Lactobacillus helveticus, J. Ind. Microbiol. Biotechnol. 18 (1997) 272. doi: https://doi.org/10.1038/sj.jim.2900379

13. Bhosale, P., Gadre R. V., Beta-Carotene production in sugarcane molasses by a Rhodotorula glutinis mutant, J. Ind. Microbiol. Biotechnol. 26 (2001) 327. doi: https://doi.org/10.1038/sj.jim.7000138

14. Buzzini, P., Martini, A., Production of carotenoids by strains of Rhodotorula glutinis cultured in raw materials of agro-industrial origin, Biores. Technol. 71 (2000) 41. doi: https://doi.org/10.1016/S0960-8524(99)00056-5

15. Alvira, P., Tomas-Pejo, E., Ballesteros, M., Negro, M. J., Pretreatment technologies for an efficient bioethanol production process based on enzymatic hydrolysis: A review, Biores. Technol. 81 (2010) 4851. doi: https://doi.org/10.1016/j.biortech.2009.11.093

16. Gnansounou, E., Dauriat, A., Techno-economic analysis of lignocellulosic ethanol: A review, Biores. Technol. 81 (2010) 4980. doi: https://doi.org/10.1016/j.biortech.2010.02.009

17. Cara, C., Ruiz, E., Ballesteros, I., Negro, M. J., Castro E., Enhanced enzymatic hydrolysis of olive tree wood by steam explosion and alkaline peroxide delignification, Process Biochem. 41 (2006) 423. doi: https://doi.org/10.1016/j.procbio.2005.07.007
18. Bobleter, O., Hydrothermal degradation and fractionation of saccharides and polysaccharides. In: S. Dumitriu. Polysaccharides: Structural Diversity and Functional Versatility, CRC Press, London, UK (2005) 893.

19. Galbe, M., Zacchi, G., Pretreatment: The key to efficient utilization of lignocellulosic materials, Biomass Bioenergy 46 (2012) 70. doi: https://doi.org/10.1016/j.biombioe.2012.03.026

20. Palmqvist, E., Hahn-Hagerdal, B., Fermentation of lignocellulosic hydrolysates II: inhibitors and mechanisms of inhibition, Biores. Technol. 74 (2000) 25. doi: https://doi.org/10.1016/S0960-8524(99)00161-3

21. Zhang, G., French, W. T., Hernandez, R., Alley, K., Paraschivescu, M., Effects of furfural and acetic acid on growth and lipid production from glucose and xylose by Rhodotorula glutinis, Biomass Bioenergy 35 (2011) 734. doi: https://doi.org/10.1016/j.biombioe.2010.10.009

22. Marova, I., Carnecka, M., Halienova, A., Koci, R., Breiero$v a, E$., Production of carotenoid/ergosterol-supplemented biomass by red yeast Rhodotorula glutinis under external stress, Food Technol. Biotechnol. 48 (2010) 56.

23. Palmqvist, E., Hahn-Hagerdal, H., Galbe, M., Larsson, M., Stenberg, K., Szengyel, Z., Tengborg, C., Zacchi, G., Design and operation of a bench-scale process development unit for the production of ethanol from lignocellulosics, Biores. Technol. 58 (1996) 171. doi: https://doi.org/10.1016/S0960-8524(96)00096-X

24. Perrier, V., Dubreucq, E., Galzy, P., Fatty acid and carotenoid composition of Rhodotorula strains, Arch. Microbiol. 164 (1995) 173 doi: https://doi.org/10.1007/BF02529968

25. Aksu, Z., Eren, A. T., Carotenoids production by the yeast Rhodotorula mucilaginosa: Use of agriculture wastes as a carbon source, Process Biochem. 40 (2005) 2985. doi: https://doi.org/10.1016/j.procbio.2005.01.011

26. Almeida, J., Modig, T., Petersson, A., Hahn-Hägerdal, B., Lidén, G., Gorwa-Grauslund, M. F., Increased tolerance and conversion of inhibitors in lignocellulosic hydrolysates by Saccharomyces cerevisiae, J. Chem. Technol. Biotechnol. 82 (2007) 340. doi: https://doi.org/10.1002/jctb.1676 